Hydrol. Earth Syst. Sci., 14, 2329-2341, 2010

www.hydrol-earth-syst-sci.net/14/2329/2010/

doi: $10.5194 /$ hess-14-2329-2010

(c) Author(s) 2010. CC Attribution 3.0 License.

\title{
An assessment of future extreme precipitation in western Norway using a linear model
}

\author{
G. N. Caroletti ${ }^{1,2}$ and I. Barstad ${ }^{1,3}$ \\ ${ }^{1}$ Bjerknes Centre for Climate Research, Bergen, Allegata 55, 5007 Bergen, Norway \\ ${ }^{2}$ Geophysical Institute, University of Bergen, Allegata 70, 5007 Bergen, Norway \\ ${ }^{3}$ Uni Research AS, Thormhlensgt. 55, 5008 Bergen, Norway
}

Received: 24 November 2009 - Published in Hydrol. Earth Syst. Sci. Discuss.: 18 December 2009

Revised: 29 October 2010 - Accepted: 9 November 2010 - Published: 26 November 2010

\begin{abstract}
A Linear Model (Smith and Barstad, 2004) was used to dynamically downscale Orographic Precipitation over western Norway from twelve General Circulation Model simulations. The GCM simulations come from the A1B emissions scenario in IPCC's 2007 AR4 report. An assessment of the changes to future Orographic Precipitation (time periods: 2046-2065 and 2081-2100) versus the historical control period (1971-2000) was performed. Results showed increases in the number of Orographic Precipitation days and in Orographic Precipitation intensity. Extreme precipitation events, as defined by events that exceede the 99.5\%-ile threshold for intensity for the considered period, were found to be up to $20 \%$ more intense in future time periods when compared to 1971-2000 values. Using stationbased observations from the control period, the results from downscaling could be used to generate simulated precipitation histograms at selected stations.

The Linear Model approach also allowed for simulated changes in precipitation to be disaggregated according to their causal source: (a) the role of topography and (b) changes to the amount of moisture delivery to the site. The latter could be additionaly separated into moisture content changes due to the following: (i) temperature, (ii) wind speed, and (iii) stability. An analysis of these results suggested a strong role of moist stability and warming in the increasing intensity of extreme Orographic Precipitation events in the area.
\end{abstract}

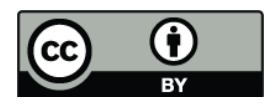

Correspondence to: G. N. Caroletti (giulio.caroletti@bjerknes.uib.no)

\section{Introduction}

Precipitation strongly and visibly influences human life and has always been a primary subject of meteorological studies. Precipitation results from a chain of different physical processes. When a precipitation event takes place, it is often difficult to identify the following: (i) which processes are at work, (ii) the temporal and (iii) spatial scales at which these processes work, and (iv) how large a part each of them plays in the event's formation and evolution.

Orographic Precipitation (OP) is of particular interest, as mountainous regions occupy about one-fifth of the Earth's surface, are home to one-tenth of the global population and directly affect about half of the worlds' population (Messerli and Ives, 1997; Becker and Bugmann, 1999). OP is the most important source of fresh water for human communities and for the environment. On the other hand, extreme OP events are often the cause of mudslides, avalanches, flash floods, dam breaks, etc. (Roe, 2005).

The need for local assessments of precipitation has grown in recent years due to increases in extreme precipitation in some areas and the widespread awareness about findings of the IPCC 2007 AR4 Report on climate change (Solomon et al., 2007). The Report predicts that, in a future warmer climate, mean precipitation will increase at tropical and high latitudes and that extreme precipitation events will increase in most tropical, mid- and high latitude areas (Meehl et al., 2007). In the IPCC 2001 AR3 Report, General Circulation Models (GCMs), which are used for climate predictions, show an increase in precipitation due to increases in greenhouse gases (Cubash and Meehl et al., 2001). It has been suggested that changes in extreme precipitation are easier to detect than changes in mean annual precipitation because

Published by Copernicus Publications on behalf of the European Geosciences Union. 
relative changes in heavy and extreme precipitation are of the same sign and are stronger than those of the mean (Groisman et al., 2005). It is also easier to attribute increases in heavy and extreme precipitation to global warming, because of higher water content in the atmosphere and correlated increases in the frequency of cumulonimbus clouds and thunderstorm activity in the extratropics (Trenberth et al., 2003; Groisman et al., 2005).

Precipitation remains one of the most difficult meteorological parameters to predict because of the following reasons:

i. Precipitation processes are parameterised in even the most complex models;

ii. in areas of complex orography, the model resolution needed to properly resolve all important precipitation processes is on the order of kilometres or even smaller units (Smith, 1979);

iii. although the thermodynamic mechanism of OP (e.g., adiabatic cooling and condensation with the uplift of air parcels) are generally known (Smith, 1979; Roe, 2005), complex topography still makes it difficult for numerical models to accurately reproduce observations (e.g., Bousquet and Smull, 2001; Georgis et al., 2003; Rotunno and Ferretti, 2003; Smith, 2003).

The challenge of matching simulated and observed precipitation is especially difficult for GCMs. GCM simulations, which provide results on coarse grids of $250-300 \mathrm{~km}$ resolution, cannot account for the observed horizontal variability that occurs on smaller scales without great computational investment.

GCM output can be refined with methods that provide local results from global ones, in a process called downscaling. Downscaling can be statistical/empirical (Wilby et al., 1998) or physical/dynamical (Déqué et al., 1995; Cooley, 2005; Coppola and Giorgi, 2005; Haylock et al., 2006; Schmidli et al., 2007; Barstad et al., 2008). Statistical downscaling is performed by finding one or more statistical relationships between large scale and finer scale variables (e.g., regression analysis), and then estimating true local distributions through these relationships. Dynamical downscaling refines large scale information by using physically based models to produce fine-scale information. The most common approach to dynamical downscaling is to use RCMs (Giorgi and Mearns, 1999; Wang et al., 2004).

Several investigations have compared dynamical and statistical downscaling methods for daily precipitation (Wilby et al., 1998; Murphy, 1999; Wilby et al., 2000) and have shown comparable performance for the two. Haylock et al. (2006) and Salathe Jr. (2005) suggest inclusion of as many models as possible when developing local climate-change projections. A comprehensive summary of developments of precipitation downscaling in climate change scenarios is found in Maraun et al. (2010).
The goal of this paper is to use a reduced approach, called the Linear Model (LM from now on; Smith and Barstad, 2004). LM has low computational demands that can be useful for dynamically downscaling simulated precipitation from large numbers of GCM runs.

In LM, cloud physics and airflow dynamics are described with a simple set of equations. LM has been used successfully both in idealised (Barstad et al., 2007) and realistic (Crochet et al., 2007) problems predicting orographyinduced precipitation. In these situations, incoming moisture is forced upslope by orography; condensation and drift of cloud-hydrometeors results in precipitation. In Barstad et al. (2007), it was shown that LM compares favorably with more elaborate numerical models when applied to orographic precipitation, despite heavily abbreviated physics. In Crochet et al. (2007), the simulated precipitation over Iceland, driven by ERA-40 reanalysis data, was in good agreement with 1958-2002 observations over various time scales, both in terms of magnitude and distribution. LM has also been used to simulate extreme precipitation events (Smith and Barstad, 2004; Barstad et al., 2007). LM has the additional benefit of being able to rigorously separate the simulated cause of changes in OP.

This study focused on western Norway, a region of steep orography characterised by heavy precipitation on its windward side. The precipitation results from strong winds on the upwind side of the mountains due to the high frequency of extra-tropical cyclones that impact the area (Andersen, 1973, 1975; Barstad, 2002). Precipitation in western Norway is dominated by forced uplift rather than thermally driven convection, so the LM's structural inability to account for convection does not constitute a severe problem. The precipitation simulations in this paper will result from the dynamical downscaling of data from 12 IPCC A1B scenario model runs (Solomon et al., 2007). The A1B scenario was chosen because it represents a moderate emission scenario.

Section 2 describes Smith and Barstads' (2004) Linear Model. Section 3 explains the methods used to downscale western Norway's OP and to compare future periods with the control period from the recent past. Section 4 explains the downscaled results, with a focus on changes in the number of OP events and the magnitude of extreme OP events; it also explains how to apply the results to station data for assessing future precipitation, and, by making use of LM's transparency, it investigates the reasons for changes in OP extremes. Section 5 gives a short discussion on the meaning of the results in the wake of future extreme precipitation studies. Section 6 provides a summary of the results and conclusions.

\section{The linear model}

The Linear Model (LM) makes use of a simple system of equations to describe the advection of condensed water by a 
Table 1. Some symbols used in the model.

\begin{tabular}{lll}
\hline Symbol & Physical property & Typical values \\
\hline$(k, l)$ & Components of the horizontal wavenumber vector & \\
$C_{\mathrm{W}}$ & Thermodynamics uplift sensitivity factor & 0.001 to $0.02 \mathrm{~kg} \mathrm{~m}^{-3}$ \\
$\sigma=U_{x} k+U_{y} l$ & Intrinsic frequency & 0.01 to $0.0001 \mathrm{~s}^{-1}$ \\
$h(x, y)$ & Height of terrain & \\
$m(k, l)$ & Vertical wavenumber & 0.01 to $0.0001 \mathrm{~m}^{-1}$ \\
$H_{\mathrm{W}}$ & Depth of moist layer (water vapour scale height) & 1 to $5 \mathrm{~km}$ \\
\hline
\end{tabular}

mean wind speed. Smith and Barstad (2004) start by considering a distributed source of condensed water $S(x, y)$ arising from forced ascent (Fig. 1). The source is the sum of the background rate of cloud water generation and local variations created by terrain-forced uplift. In the special case where the background rate is put to 0 , Smith and Barstad (2004) propose an upslope model

$S(x, y)=C_{\mathrm{W}} \mathbf{U} \cdot \nabla h(x, y)$,

where $C_{\mathrm{W}}=\rho_{\mathrm{S}_{\mathrm{ref}}} \frac{\Gamma_{\mathrm{m}}}{\gamma}$ is the coefficient relating condensation rate to vertical motion, $h(x, y)$ is the terrain and the terrainforced vertical air velocity $w(x, y)=\mathbf{U} \cdot \nabla h(x, y)$ is independent of altitude. $\Gamma_{\mathrm{m}}$ is the moist adiabatic lapse rate, $\gamma$ is the environmental lapse rate, and $\rho_{\mathrm{S}_{\mathrm{ref}}}=e_{\mathrm{S}}\left(T_{\mathrm{ref}}\right) / R T_{\text {ref }}$, where $e_{\mathrm{S}}$ is the saturation vapor pressure, $T_{\text {ref }}$ is the temperature at the ground, and $R=461 \mathrm{~J} \mathrm{~kg} \mathrm{~K}^{-1}$ is the gas contant for vapor.

In Fourier space, Eq. (1) becomes

$\hat{S}(k, l)=\frac{C_{\mathrm{W}} i \sigma \hat{h}(k, l)}{\left(1-i m H_{\mathrm{W}}\right)}$

assuming saturated conditions and including wave dynamics, where $\sigma=U_{x} k+U_{y} l$ is the intrinsic frequency, $m(k, l)=\left[\left(\frac{N_{\mathrm{m}}^{2}-\sigma^{2}}{\sigma^{2}}\right)\left(k^{2}+l^{2}\right)\right]^{1 / 2}$ is the vertical wavenumber, and $H_{\mathrm{W}}=-R \frac{T_{\mathrm{ref}}^{2}}{L \gamma}$ is the water vapor scale height, with $L=2,5 \times 10^{6} \mathrm{~J} \mathrm{~kg}^{-1}$ being the latent heat (see Table 1 for further explanation of the symbols used; see Smith and Barstad, 2004, for a full calculation of the source term in Fourier space). Variables in Fourier space are denoted by the symbol of hat.

By following Smith's (2003) steady-state advection equations describing the vertically integrated cloud water density $q_{\mathrm{c}}(x, y)$ and hydro-meteor density $q_{\mathrm{s}}(x, y)$, the following equation is derived:

$$
\begin{aligned}
& \frac{D q_{\mathrm{c}}}{D t} \approx \mathbf{U} \cdot \nabla q_{\mathrm{c}}=S(x, y)-\frac{q_{\mathrm{c}}}{\tau_{\mathrm{c}}} \\
& \frac{D q_{\mathrm{s}}}{D t} \approx \mathbf{U} \cdot \nabla q_{\mathrm{s}}=\frac{q_{\mathrm{c}}}{\tau_{\mathrm{c}}}-\frac{q_{\mathrm{s}}}{\tau_{\mathrm{f}}},
\end{aligned}
$$

where the final term in Eq. (4) is the loss of hydrometeors associated with precipitation, $P(x, y)=q_{\mathrm{s}}(x, y) / \tau_{\mathrm{f}}$.

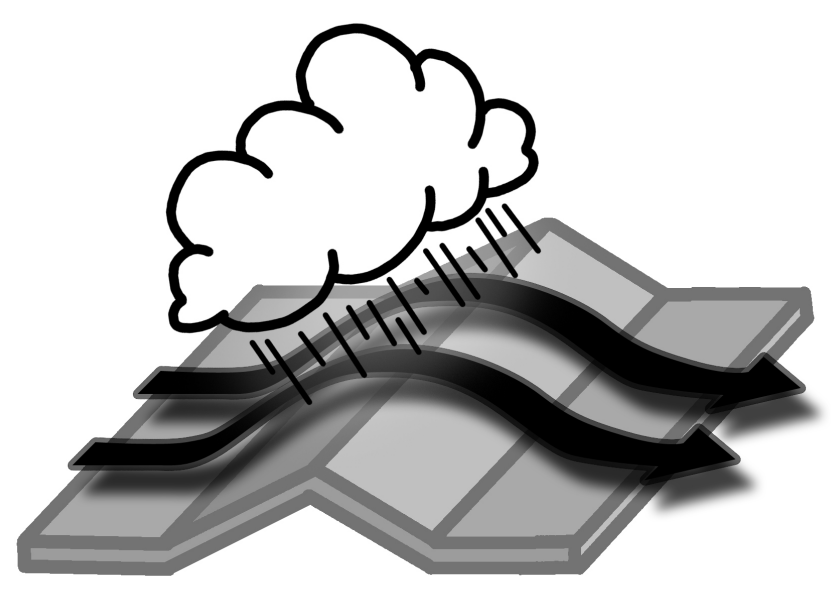

Fig. 1. A schematic illustration of orographic precipitation as the result of stable upslope ascent. Illustration by Marco Caradonna (2009), based on a figure from Roe (2005).

Applying simple algebra, an expression for the Fourier transform of the precipitation distribution $\hat{P}$ is obtained, as follows:

$$
\hat{P}(k, l)=\frac{\hat{S}(k, l)}{\left(1+i \sigma \tau_{\mathrm{c}}\right)\left(1+i \sigma \tau_{\mathrm{f}}\right)},
$$

which is dependent on the source $S(x, y)$ and considers time delays (the conversion and fall-out terms $\tau_{\mathrm{c}}$ and $\tau_{\mathrm{f}}$ ).

Combining Eqs. (2) and (5) yields a "transfer function" relating the Fourier transform of the terrain $\hat{h}$ and the precipitation field $\hat{P}$ :

$$
\hat{P}(k, l)=\frac{C_{\mathrm{W}} i \sigma \hat{h}(k, l)}{\left(1-i m H_{\mathrm{W}}\right)\left(1+i \sigma \tau_{\mathrm{c}}\right)\left(1+i \sigma \tau_{\mathrm{f}}\right)},
$$

in which the denominator's factors represent airflow dynamics (first term), cloud delays and advection (second and third terms, respectively).

The precipitation distribution is then obtained with the use of an inverse Fourier transform

$$
P(x, y)=\int_{-\infty}^{\infty} \int_{-\infty}^{\infty} \hat{P}(k, l) e^{i(k x+l y)} d k d l .
$$


In short, the LM describes the effect of orography and mean wind on precipitation, and, with some complexity, the effects of temperature, humidity, moist stability, conversion and fallout times of hydrometeors.

\section{Source term breakdown}

LM can also be used to understand the mechanisms behind downscaled changes in OP extremes.

From now on, we will use $N=N_{\mathrm{m}}, T=T_{\text {ref. }}$.

Smith and Barstad (2004) have shown that the moisture influx magnitude $(F)$ depends on saturation water vapour density at the ground $\rho_{\mathrm{S}_{\text {ref }}}(T)$, water vapour scale height $H_{\mathrm{W}}(N, T)$ and wind speed $U$ :

$F=\rho_{\mathrm{S}_{\mathrm{ref}}} H_{\mathrm{W}} U$.

There is a linear relationship between the moist air influx and the precipitation in LM: by comparing Eqs. (1) and (8) we get:

$S=\frac{F}{H_{\mathrm{W}}} \frac{\Gamma_{\mathrm{m}}}{\gamma} \nabla h(x, y)=\rho_{\mathrm{S}_{\mathrm{ref}}} U \frac{\Gamma_{\mathrm{m}}}{\gamma} \nabla h(x, y)$.

By using the relationship between lapse rates and moist static stability (Fraser et al., 1973) $N^{2}=g \frac{\gamma-\Gamma_{\mathrm{m}}}{T}$ and remembering that $H_{\mathrm{W}}=-R \frac{T^{2}}{L \gamma}$ we get:

$\Gamma_{\mathrm{m}}=\gamma-\frac{N^{2} T}{g}$

$\gamma=-\frac{R T^{2}}{L H_{\mathrm{W}}}$

Thus:

$S=\rho_{\mathrm{S}_{\mathrm{ref}}} U\left[\frac{N^{2} H_{\mathrm{W}} L}{g R T}+1\right] \nabla h(x, y)$.

Notwithstanding the orography, the change in the source term will be fully determined by the change in temperature, stability and wind magnitude: to establish their influence on the source, we calculate the source term in Eq. (11) by varying only one of the variables at a time. A mixing term of $T$ and $N^{2}$, that comes from the fact that $H_{\mathrm{W}}=H_{\mathrm{W}}(N, T)$, remains unaccounted for, but it is shown to be small.

\section{Downscaling GCMs}

The use of LM for downscaling may help to bridge the gap between poorly resolved GCM data and the need for detailed precipitation data. Variables and parameters used for input in the LM are shown in Table 2. GCMs' precipitation output has not been used. Precipitation intensity was calculated in $\mathrm{mm} /$ day.

21 models were used for A1B scenario testing, for a total of 41 model runs. Not all of them were available due to incomplete data sets or other inconsistencies that could
Table 2. Model inputs.

\begin{tabular}{lll}
\hline Input Variable & Symbol & Data Source \\
\hline Wind & $\mathbf{U}$ & GCM data \\
Temperature & $T$ & GCM data \\
Moist static stability & $N_{\mathrm{m}}$ & GCM data \\
Humidity & $q$ & GCM data \\
Relative humidity & RH & GCM data \\
Terrain & $h$ & DEM topography \\
Conversion time & $\tau_{\mathrm{c}}$ & User defined as $1000 \mathrm{~s}$ \\
Fallout time & $\tau_{\mathrm{f}}$ & User defined as $1000 \mathrm{~s}^{-1}$ \\
Background precipitation & - & User defined as $0 \mathrm{~mm} \mathrm{~h}^{-1}$ \\
\hline
\end{tabular}

affect the plausibility of the final results. Those with missing data were dismissed, as were those showing unreasonable predictions for temperature in western Norway (annual average temperature between $40^{\circ} \mathrm{C}$ and $0{ }^{\circ} \mathrm{C}$ ). Our final selection is based on 12 simulations from 10 GCMs (Table 3 ). By using an ensemble mean, the trends in precipitation and extreme event intensity are not hidden by the annual variability in individual model runs.

The A1B scenario provides daily data for horizontal wind $(U, V)$, temperature $T$ and moist stability frequency $N_{\mathrm{m}}$. These are constant mean values for the whole domain, and are updated daily. Conversion and fallout times were set to $1000 \mathrm{~s}$. Typical conversion times are between $200 \mathrm{~s}$ and 2000 s (Smith, 2003); longer residence times within clouds result in precipitation delay. The time delay $\tau=1000 \mathrm{~s}$ values were not expected to be exact, but generally summarised the combined effects of many cloud physics processes (Barstad and Smith, 2005), and have been used in LM for studies at the regional scale (Smith, 2006; Crochet et al., 2007). Longer time delays typically result in more precipitation being advected past regions of steep topography, increased precipitation on the lee side of the topography and lower overall precipitation intensity. Conversely, shorter time delays result in more intense rain being shifted upwind (Smith and Barstad, 2004; Barstad et al., 2007).

The LM's grid corresponds to the Digital Elevation Model (DEM) GTOPO30 topography grid, and has a resolution of $30^{\prime \prime}$. At a latitude of $60^{\circ}$, this corresponds to an average grid spacing of about $450 \mathrm{~m} \times 900 \mathrm{~m}$, which is sufficient to resolve important scales affecting OP.

Our first step was to identify OP events. The only days considered in our study were those with a relative humidity above or equal to $85 \%$. This is because lower relative humidities result in relatively weak to no OP (Barstad et al., 2007). In addition, only days with prevailing wind directions between $180^{\circ}$ and $300^{\circ}$ (westerly winds) were considered, as they are the only ones to give rise to significant OP (Barstad, 2002).

The second step of the study was to identify days with extreme OP. There are several possible ways of defining an 
Table 3. Downscaled IPCC model runs.

\begin{tabular}{clcl}
\hline Model Run Number & Model Run Name & Model Run Number & Model Run Name \\
\hline 1 & gfdl_cm2_1 & 7 & cnrm_cm3_1 \\
2 & gfdl_cm2_0 & 8 & miroc_hires \\
3 & mri_cgcm2_3_2a_1 & 9 & miroc_medres \\
4 & cccma_cgcm3_1_t47 run 1 & 10 & mpi_echam5 \\
5 & cccma_cgcm3_1_t47 run 2 & 11 & cccma_cgcm3_1_t63 \\
6 & cccma_cgcm3_1_t47 run 3 & 12 & bccr_bcm2_0 \\
\hline
\end{tabular}

extreme event. One method is to use the tails of a climatological distribution, through the use of quantiles (Jones, 2000; Cooley, 2005). A second alternative ("peak-over-threshold" method) is to consider as extreme any result exceeding a certain threshold value (Cooley, 2005). An advantage of using the percentile method when performing model-comparison is that it is a relative method that can be used for all model runs, thus providing consistency.

In this paper, the $99.5 \%$-ile of the distribution was used to define the cut-off for an extreme OP event. Different models use different parameterisations, and we do not definitively know which ones are most appropriate for a future situation. Thus, looking at absolute values could be misleading (Klein Tank and Können, 2003). Instead, we compared the extreme OP intensities in future periods to the control period data within each simulation. If the simulations from different models agreed on a relative increase, then it was more likely to be a consequence of the climate change signal from scenarios and not a result of individual model variations.

To determine the extreme threshold we have supposed that the generalized Pareto distribution is valid as a model for the excesses of a threshold generated by the precipitation series. The thresholds depended on the model run simulations, and their values were located between the 99 and $99.9 \%$-ile of the distribution. The results suggested that the choice of $99 \%$-ile was too low for some of the model runs, whereas the 99.9\%ile was found too high, as this choice of threshold gave too few exceedances to make meaningful inferences (see Coles, Ch. 4.3.1 "Modeling Threshold Excesses" on threshold selection).

The model domain falls between $57^{\circ} 30^{\prime}$ and $64^{\circ} 20^{\prime} \mathrm{N}$ and $4^{\circ}$ and $10^{\circ} 40^{\prime} \mathrm{E}$. This includes all of southern Norway (Fig. 2). In this area we selected the 74 grid points nearest to weather stations that were active and measured precipitation during the entire control period of 1971-2000. The stations were all located in Western Norway and are listed in Table 4.

\section{LM validation for western Norway}

To show that LM might be an adequate tool for downscaling precipitation in western Norway, we performed LMdownscaling on ERA40 reanalysis data and compared it with ERA40 and observational precipitation data for extreme

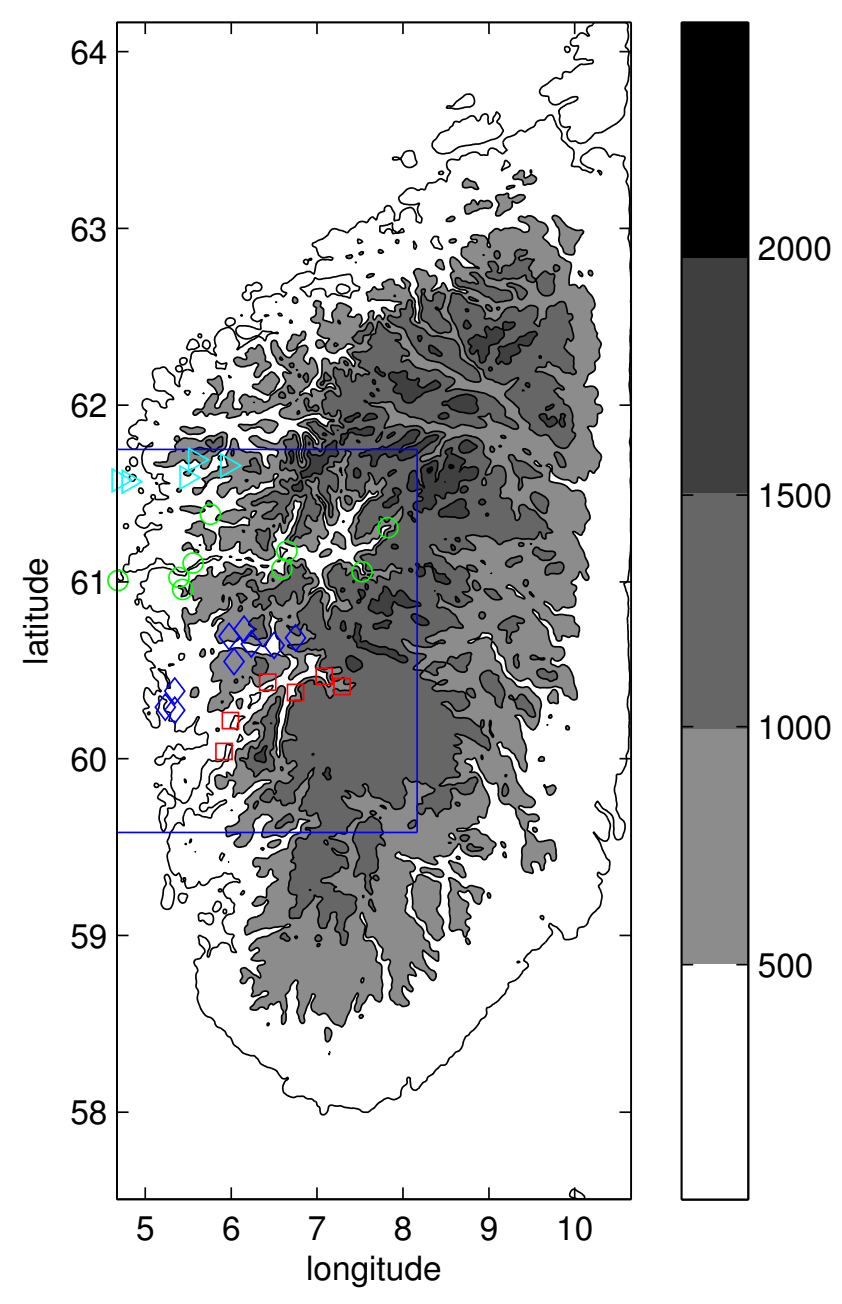

Fig. 2. The domain area. Mountains were smoothed near the boundaries to avoid numerical instabilities. The points show the location of the meteorological stations used for the cross-sections in Sect. 4 (see also Fig. 5).

events at our 74 stations. The period of comparison was 1971-1999, which included almost all of the control period for GCMs in our study (1971-2000).

In our operational setup, LM did not have any background precipitation. Thus, its output was purely OP. ERA40 
Table 4. Observational stations in western Norway used in the article.

\begin{tabular}{llllllll}
\hline$\#$ & name & $\#$ & name & $\#$ & name & name \\
\hline 1 & Eikefjord & 20 & Hafslo & 39 & Skei & 58 & Tysse \\
2 & Kinn & 21 & Sogndal Selseng & 40 & Botnen & 59 & Kvamskogen \\
3 & Ytteroeyane Fyr & 22 & Gjengedal & 41 & Aalfoten II & 60 & Samnanger \\
4 & Groendalen & 23 & Sandane & 42 & Roeldal & 61 & Fana Stend \\
5 & Takle & 24 & Myklebust & 43 & Roeldal Kraftverk & 62 & Flesland \\
6 & Brekke & 25 & Innvik & 44 & Midtlaeger & 63 & Bergen GFI \\
7 & Vik III & 26 & Briksdal & 45 & Etne & 64 & Kaldestad \\
8 & Vangsnes & 27 & Sindre & 46 & Litledal & 65 & Oevstedal \\
9 & Myrdal IV & 28 & Hornindal & 47 & Eikemo & 66 & Brekkhus \\
10 & Aurland & 29 & Stadlandet & 48 & Tyssedal I & 67 & Bulken \\
11 & Laerdal & 30 & Fjaerland Skarestad & 49 & Skjeggedal II & 68 & Voss \\
12 & Borlo & 31 & Roeyrvikvatn & 50 & Tyssedal III & 69 & Reimegrend \\
13 & Maristova & 32 & Lavik & 51 & Tyssedal IV & 70 & Fjellanger \\
14 & Oevre Aardal & 33 & Ytre Solund & 52 & Kinsarvik & 71 & Eksingedal \\
15 & Haukeland & 34 & Hovlandsdal & 53 & Eidfjord & 72 & Gullbraa \\
16 & Fortunen & 35 & Guddal & 54 & Fet & 73 & Eikanger \\
17 & Skagen & 36 & Dale II & 55 & Nedre Aalvik & 74 & Hellisoey Fyr \\
18 & Skaalavatn & 37 & Haukedal & 56 & Omastrand & & \\
19 & Froeyset & 38 & Osland & 57 & Hatlestrand & & \\
\hline
\end{tabular}

reanalysis precipitation is the sum of large-scale/frontal precipitation and convective precipitation. Our work hypothesis was that in western Norway the background precipitation is much smaller than OP during extreme events, so that $\mathrm{OP} \simeq$ total precipitation. To perform a plausible assessment of future extreme events, there was the need to see if and where this happened in the region.

Figure 3 shows an example of the comparison. On coastal stations with low orography, the $\mathrm{OP} \simeq$ total precipitation hypothesis broke down, and LM was not able to reproduce the extreme precipitation. Instead, at inland and mountain stations, LM was able to reproduce the extreme precipitation with good results. Not only were LM's extreme values quantitatively close to the observed ones; LM was also able to reproduce the spatial gradient in the region. This last feature happened also closer to the coast. In Fig. 3 it shows how ERA40 was unable to account for the right sign in the extreme values gradient along the crossection from station no. 3 to station no. 2. Both of these features showed up also for the other crossections and stations throughout the domain area.

As seen in Sect. 2, LM's transparency allowed to separate the source term in basic components. We compared values of wind speed, wind direction, temperature and stability associated to observed extreme events and LM-downscaled extreme events at various stations to check whether LM was able to correctly reproduce their values during extreme events. An example is shown for the Bergen-GFI station (see below, Chapter 4, for more informations on this station). Bergen-GFI has an observed $99.5 \%$-ile of $58 \mathrm{~mm} /$ day,

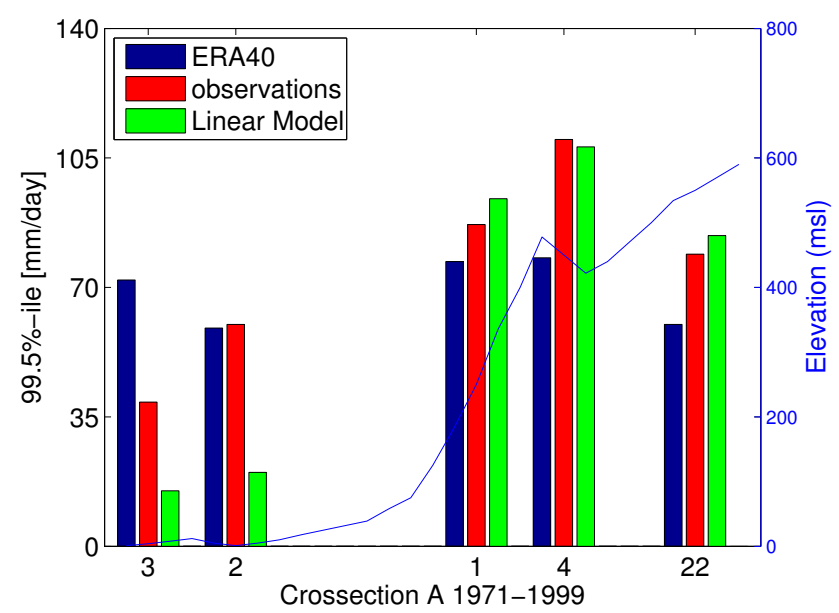

Fig. 3. 99.5\%-ile for precipitation, 1971-1999, for Crossection A. ERA40 reanalysis and ERA40-driven LM simulation compared to data from the Norwegian Meteorological Institute. Names corresponding to station numbers in figure are given in Table 4.

well comparable with the $\mathrm{LM}$ value of $63 \mathrm{~mm} /$ day (whereas ERA40's value is $97 \mathrm{~mm} /$ day). Figure 4 shows that temperature and stability during the observed extreme events overlapped with the modelled ones, while wind speed was too high during modelled events when compared to observed ones. Through a comparison of wind directions (not shown), it was possible to see that: (1) observed extreme events only occurred at directions comprised between $180^{\circ}$ and $300^{\circ}$ 
Table 5. Days with orographic precipitation. Future vs. control scenarios, mean days with OP/year and relative increase, 12 model runs, Bergen-GFI station.

\begin{tabular}{llrrrrrr}
\hline & Model run & 1971-2000 & \multicolumn{2}{c}{$2046-2065$} & & \multicolumn{2}{c}{$2081-2100$} \\
\cline { 7 - 8 } \cline { 6 - 7 } & & days/year & days/year & \% increase & & days/year & $\%$ increase \\
\hline 1 & gfdl_cm2_1 & 137 & 152 & $+11 \%$ & & 170 & $+24 \%$ \\
2 & gfdl_cm2_0 & 103 & 113 & $+10 \%$ & & 122 & $+18 \%$ \\
3 & mri_cgcm2_3_2a_1 & 88 & 97 & $+10 \%$ & & 101 & $+14 \%$ \\
4 & cccma_cgcm3_1_t47 run 1 & 123 & 136 & $+11 \%$ & & 132 & $+7 \%$ \\
5 & cccma_cgcm3_1_t47 run 2 & 125 & 129 & $+3 \%$ & & 142 & $+14 \%$ \\
6 & cccma_cgcm3_1_t47 run 3 & 127 & 141 & $+11 \%$ & & 130 & $+3 \%$ \\
7 & cnrm_cm3_1 & 113 & 127 & $+13 \%$ & & 143 & $+26 \%$ \\
8 & miroc_hires & 104 & 114 & $+9 \%$ & & 119 & $+14 \%$ \\
9 & miroc_medres & 119 & 127 & $+7 \%$ & & 126 & $+6 \%$ \\
10 & mpi_echam5 & 146 & 152 & $+4 \%$ & & 162 & $+11 \%$ \\
11 & cccma_cgcm3_1_t63 & 135 & 150 & $+11 \%$ & & 147 & $+9 \%$ \\
12 & bccr_bcm2_0 & 86 & 117 & $+27 \%$ & & 118 & $+42 \%$ \\
& ensemble MEAN & 117 & 130 & $+10 \%$ & & 134 & $+16 \%$ \\
& std & 19 & 17 & $6 \%$ & & 20 & $11 \%$ \\
\hline
\end{tabular}

Table 6. $99.5 \%$-ile of orographic precipitation for 12 model runs, Bergen-GFI station.

\begin{tabular}{clcrrrr}
\hline & Model run & $1971-2000$ & 2046-2065 & \% increase & 2081-2100 & $\%$ increase \\
\hline 1 & gfdl_cm2_1 & 53.4 & 59.1 & $+11 \%$ & 59.4 & $+11 \%$ \\
2 & gfdl_cm2_0 & 52.2 & 58.1 & $+11 \%$ & 61.6 & $+18 \%$ \\
3 & mri_cgcm2_3_2a_1 & 51.3 & 56.9 & $+11 \%$ & 59.4 & $+15 \%$ \\
4 & cccma_cgcm3_1_t47 run 1 & 58.2 & 62.3 & $+7 \%$ & 64.2 & $+10 \%$ \\
5 & cccma_cgcm3_1_t47 run 2 & 58.2 & 62.5 & $+7 \%$ & 64.6 & $+11 \%$ \\
6 & cccma_cgcm3_1_t47 run 3 & 58.2 & 63.6 & $+9 \%$ & 64.7 & $+11 \%$ \\
7 & cnrm_cm3_1 & 49.0 & 51.3 & $+5 \%$ & 55.4 & $+13 \%$ \\
8 & miroc_hires & 64.5 & 75.0 & $+16 \%$ & 79.3 & $+23 \%$ \\
9 & miroc_medres & 56.1 & 66.5 & $+19 \%$ & 71.6 & $+28 \%$ \\
10 & mpi_echam5 & 56.7 & 64.9 & $+15 \%$ & 65.0 & $+15 \%$ \\
11 & cccma_cgcm3_1_t63 & 58.9 & 65.5 & $+11 \%$ & 68.3 & $+16 \%$ \\
12 & bccr_bcm2_0 & 45.2 & 49.8 & $+10 \%$ & 51.7 & $+14 \%$ \\
& ensemble MEAN & 55.1 & 61.3 & $+11 \%$ & 63.8 & $+15 \%$ \\
& std & & & $4 \%$ & & $5 \%$ \\
\hline
\end{tabular}

(consistent with our work hypothesis, see above); (2) the wind directions at modelled extreme events always occurred in the intervals of wind directions at observed events $\left(184^{\circ}-\right.$ $200^{\circ}$; around $260^{\circ} ; 220-230^{\circ} ; 290^{\circ}-300^{\circ}$ ). These directions are linked to local orography.

\section{GCM-downscaling results}

For illustrative purposes, we first analysed the results for a single station. The chosen station was Bergen-GFI, (lat; lon; height $)=\left(60,38^{\circ} \mathrm{N} ; 5,33^{\circ} \mathrm{E} ; 22 \mathrm{~m}\right.$ a.s.l. $)$. All model runs showed an increase in OP days in the future periods relatively to the control period, although not all agreed on whether there would be more days with OP in the first or the second future period. Table 5 shows the change in the absolute number of days with OP and the associated relative increase for each model and the ensemble mean.

The ensemble's $99.5 \%$-ile for the control scenario was $55 \mathrm{~mm} /$ day, in good agreement with the observed $58 \mathrm{~mm} /$ day. In order to evaluate the relative change in extreme OP intensity from the control period to the future periods, we normalised the absolute 20 -year $99.5 \%$-ile of every model to that of its own control period's 30-year 99.5\%-ile. The result of this procedure for both future periods is shown in Table 6. All models showed an increase in the intensity of OP extremes. The mean ensemble results showed strong $10 \%$ and $16 \%$ increases in extreme OP for the 2046-2065 and 2081-2100 

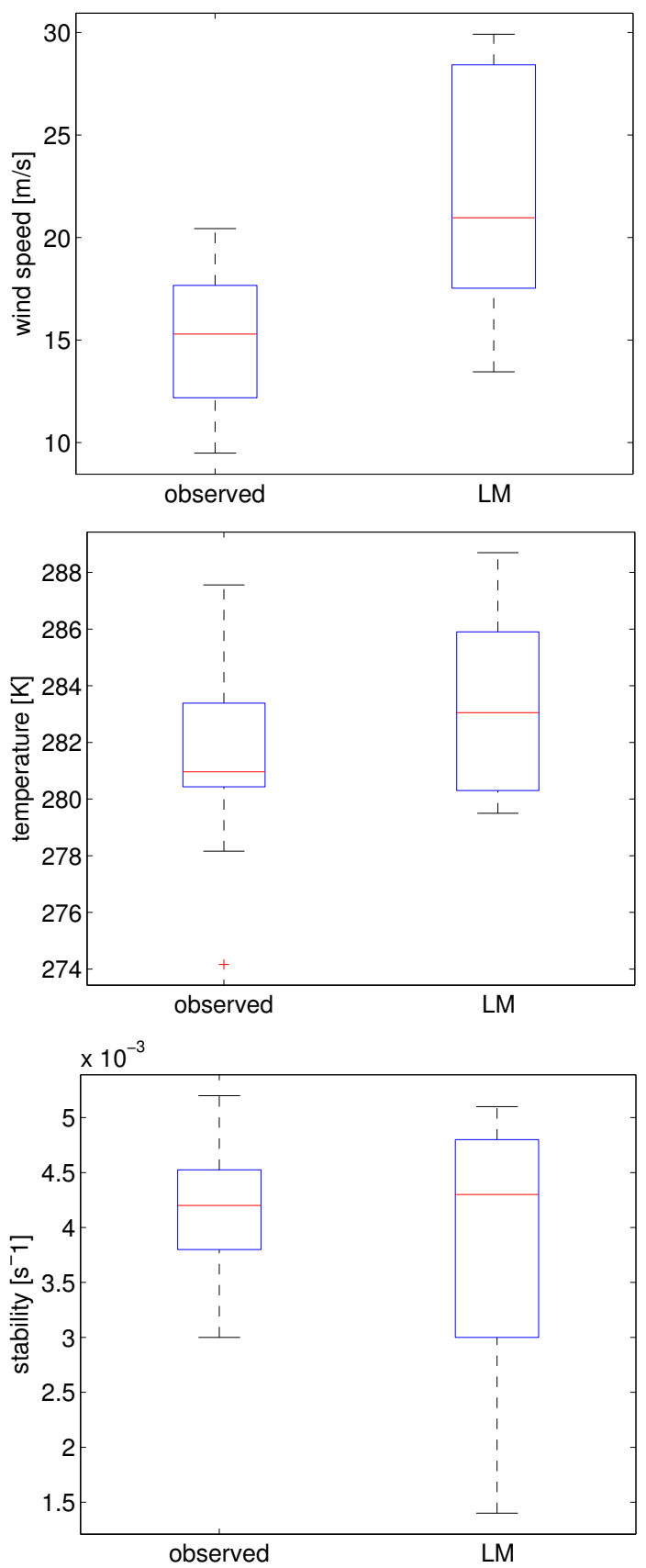

Fig. 4. Comparison of wind speed, temperature and stability values during extreme events at Bergen GFI station, 1971-1999. Observations are compared to GCM values used for LM downscaling.

intervals, respectively. The standard deviations associated to the twelve models were $4 \%$ and $5 \%$ respectively. The mean ensemble's increases for the original GCM data were $12 \%$ and $20 \%$, with associated standard deviations of $6 \%$ and $8 \%$ respectively.

A time evolution plot of the 5-years running mean's 99.5\%-ile of OP is shown in Fig. 5, with the standard deviation taken into account. The ensemble's running mean

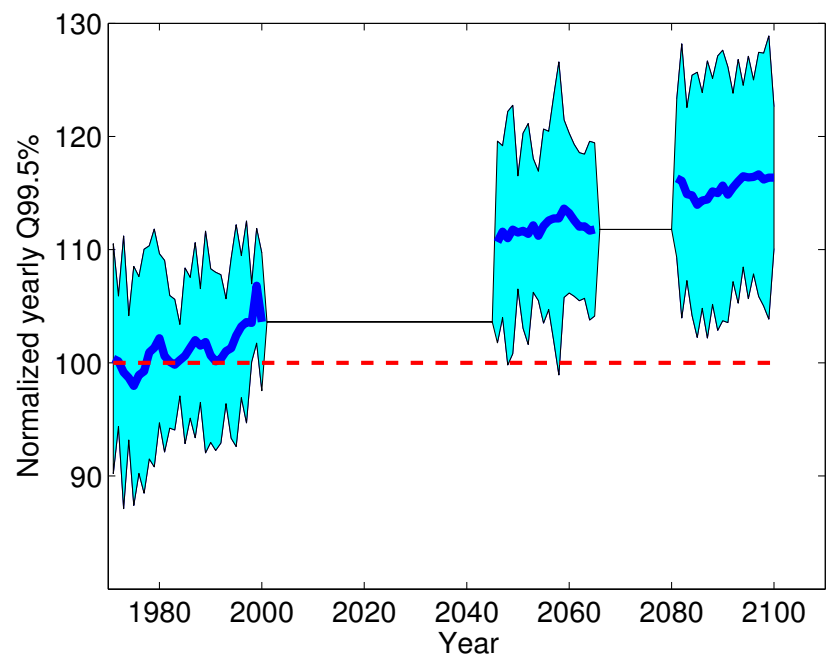

Fig. 5. Yearly mean extremes with 12-model-runs yearly standard deviation shaded in cyan. The dotted line shows the 1971-2000 30 -years-averaged mean extreme OP. The time evolution of the ensemble mean 99.5th percentile of OP is performed by calculating the yearly 99.5 th percentile for every year and every model run in our study, then performing a 5-years running mean.

was performed so that the trend in extreme event intensity was not hidden by the annual variability in individual model runs. There was the suggestion of an increase in the intensity of the extreme events at the station, albeit with a high level of noise caused by annual variability. To see how significant our mean result was, we performed a Welch's t-test. This test is used to compare independent samples with unequal sizes, a necessary requirement in this case because the control scenario was comprised of daily values for 30 years, whereas the future ones were for a 20-year period. T-tests were run to check the possibility of overlap between the control scenario extreme precipitation and future ones. With $95 \%$ confidence, the t-test rejected any overlap: the 2046-2065 time period had a OP $99.5 \%$-ile $9 \%$ to $12 \%$ higher than the control scenario, whereas the 2081-2100 time period had a OP $99.5 \%$-ile $13 \%$ to $16 \%$ higher than the control scenario.

To see if there was a change in OP patterns as the moist air proceeded into the fjords and mountains, we looked at four sections perpendicular to the coast (named A to $\mathrm{D}$ from north to south). The positions of the stations are shown in Fig. 6. The four cross-sections allowed to observe the effect on precipitation of the ascension of air along its most favourable path (Fig. 7). All showed a strong increase in OP extremes in future periods with respect to the control scenario. There was also an increase in OP extremes from the 2046-2065 period to the 2081-2100 period.

The largest relative increase in extreme OP intensity was predicted on the coast. The coastal stations, however, exhibited the weakest absolute values; when comparing the extremes at control scenarios, the modelled values were often too low, especially for stations with low orography (see also 
Table 7. Increase in extreme OP intensities by geographic setting, future vs control scenario. "Mountain" stations are inland stations located above $400 \mathrm{~m}$ a.s.l.

\begin{tabular}{lrc}
\hline Geographic setting & 2046-2065 & 2081-2100 \\
\hline Coast (7 stations) & $13 \%$ & $19 \%$ \\
Fjord (29 stations) & $10 \%$ & $14 \%$ \\
Inland (22 stations) & $9 \%$ & $14 \%$ \\
Mountain (16 stations) & $9 \%$ & $14 \%$ \\
Mean of all 74 stations & $10 \%$ & $15 \%$ \\
\hline
\end{tabular}

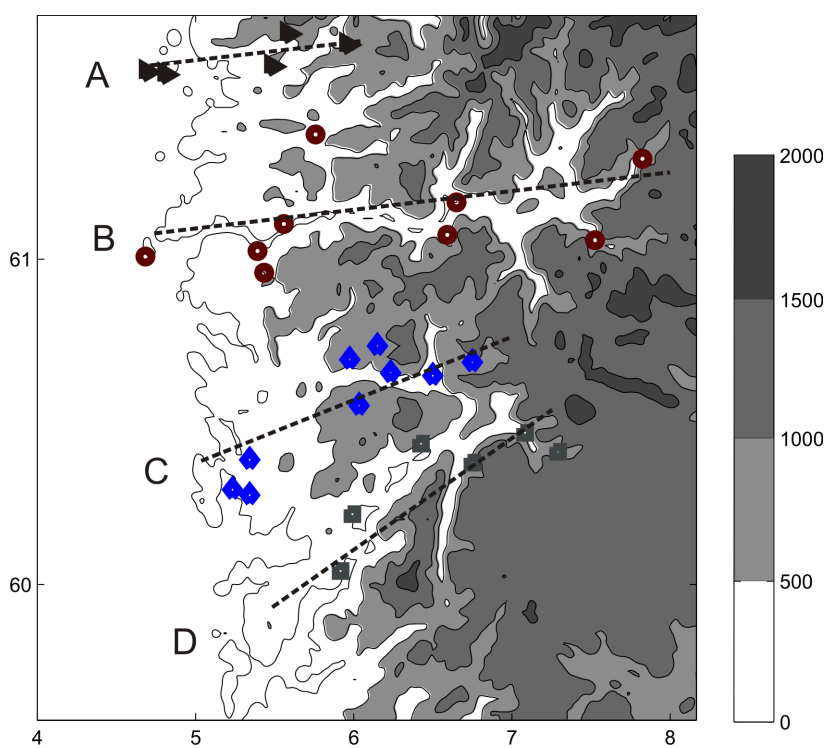

Fig. 6. Position of four sections on Norways' western coast. The stations' locations are shown on the map.

Sect. 3). Table 7 groups all 74 stations in coastal, fjord, inland and mountain stations according to their proximity to the coast and elevation. An almost $20 \%$ increase in extreme OP intensities was predicted for coastal stations over the 2081-2100 time period when compared to 1971-2000, whereas results of about $14 \%$ in 2081-2100 where predicted for the other stations.

\subsection{Assessment}

Station observations, provided by the Norwegian Meteorological Institute, can be used as a basis for assessing future precipitation changes. In Sect. 3 we showed how some stations' extreme precipitation could not be represented by LM's extreme OP. Those stations were thus discarded and considered unfit for an LM-based assessment. For the other stations, we applied the average relative increases in downscaled OP extremes to the station data to generate an estimate of the future absolute intensities of extreme precipitation.
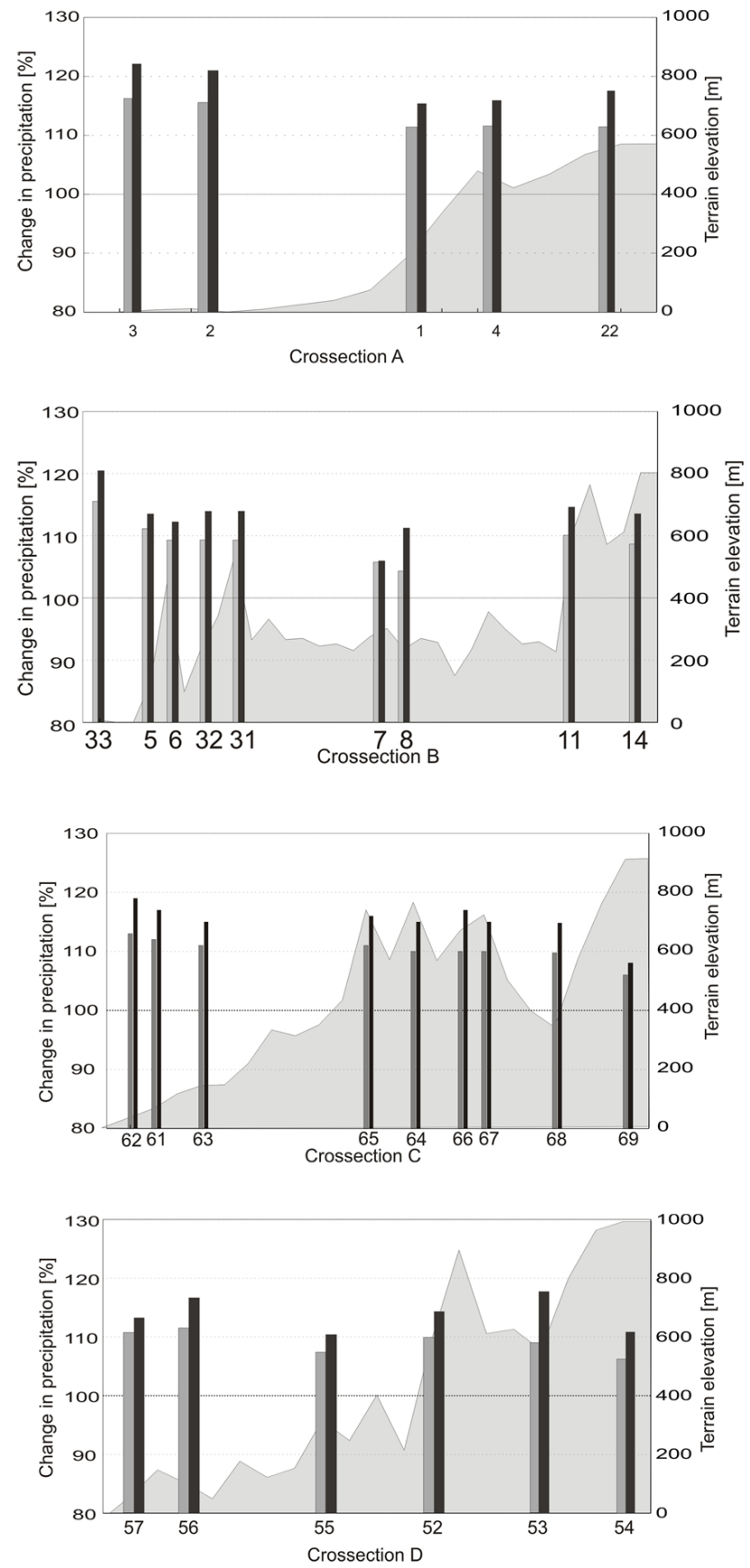

Fig. 7. Twelve-model-runs relative increase in extreme OP for four sections of Norways' western coast. The stations' locations were also shown in Fig. 5. The names corresponding to the numbers are shown in Table 4. The gray shading shows the height a.s.l. along the sections.

Table 8 shows the $99.5 \%$-ile of $1971-2000$ OP extremes for cross section A - both observed and LM-modelled. The two coastal stations are discarded from the assessment. Applying the relative increase for each individual station from the LM to the others results in the 2046-2065 and 2081-2100 
Table 8. Cross-section A. Extreme OP intensity of station data from Norwegian Meteorological Institute and assessment of future OP extremes.

\begin{tabular}{|c|c|c|c|c|c|c|}
\hline \multirow[t]{3}{*}{ Station } & \multirow{2}{*}{\multicolumn{2}{|c|}{$\frac{1971-2000}{\text { extreme (mm/day) }}$}} & \multicolumn{2}{|c|}{ 2046-2065 } & \multicolumn{2}{|c|}{ 2081-2000 } \\
\hline & & & \multirow{2}{*}{$\begin{array}{c}\text { LM increase } \\
(\%)\end{array}$} & \multirow{2}{*}{$\begin{array}{l}\text { assessment } \\
(\mathrm{mm} / \text { day })\end{array}$} & \multirow{2}{*}{$\begin{array}{c}\text { LM increase } \\
(\%)\end{array}$} & \multirow{2}{*}{$\begin{array}{l}\text { assessment } \\
(\mathrm{mm} / \text { day })\end{array}$} \\
\hline & observed & modelled & & & & \\
\hline Ytterøyane Fyr & 39 & 15 & - & NA & - & NA \\
\hline Kinn & 60 & 20 & - & NA & - & NA \\
\hline Eikfjord & 87 & 94 & $12 \pm 4$ & $97 \pm 3$ & $16 \pm 6$ & $101 \pm 5$ \\
\hline Grøndalen & 110 & 108 & $12 \pm 4$ & $123 \pm 4$ & $16 \pm 7$ & $128 \pm 8$ \\
\hline Gjengedal & 79 & 84 & $10 \pm 4$ & $87 \pm 3$ & $17 \pm 7$ & $92 \pm 6$ \\
\hline
\end{tabular}

Table 9. Reasons for the increase in extremes of 2046-2065 OP days for the Bergen meteorological station compared to 1971-2000 OP days. The total $\%$ increase is the sum of the $\%$ influx parts (temperature, stability, windspeed and mixing error) and the $\%$ wind direction part.

\begin{tabular}{crrrrrr}
\hline Model run & Total \% increase & wind direction & wind speed & temperature & stability & mixing error \\
\hline 1 & +10.8 & -1.2 & +3.8 & +2.0 & +6.1 & +0.1 \\
2 & +10.6 & -7.7 & +12.6 & +1.7 & +4.4 & -0.4 \\
3 & +11.3 & -5.3 & +2.1 & +1.5 & +12.2 & +0.8 \\
4 & +6.6 & +14.0 & -7.5 & +1.7 & -1.6 & +0.0 \\
5 & +6.6 & +0.6 & +3.0 & +1.7 & +1.6 & +0.5 \\
6 & +9.4 & +0.0 & +3.1 & +2.1 & +3.6 & +0.6 \\
7 & +4.9 & -18.6 & +9.3 & +0.8 & +12.8 & +0.6 \\
8 & +16.5 & +11.8 & +0.3 & +4.4 & +0.0 & +0.0 \\
9 & +19.0 & +18.6 & -8.5 & +4.9 & +4.2 & -0.2 \\
10 & +15.0 & -3.0 & +7.6 & +2.2 & +8.0 & +0.2 \\
11 & +10.6 & -6.0 & +10.0 & +2.5 & +3.5 & +0.6 \\
12 & +11.1 & +1.2 & +3.9 & +1.6 & +4.2 & +0.2 \\
\hline
\end{tabular}

estimates. For instance, for Gjengedal, the 30 years observed $99.5 \%$-ile for OP was found to be $79 \mathrm{~mm} /$ day. The LMensemble indicates an increase in Gjengedal OP extreme intensities for the 2046-2065 time period of about 10\%, with an associated standard deviation of $4 \%$. Thus, the absolute value for the 2046-2065 time period was $87 \mathrm{~mm} /$ day, with a standard deviation of $3 \mathrm{~mm} /$ day.

The LM projections were favourably compared to the GCM ones. Considering for example only the results for Crossection A, we saw that an ensemble of GCM results, bilinearily interpolated for the chosen stations, could not account for any difference between the five stations: they always gave a precipitation increase of $12 \%$, with a $6 \%$ standard deviation at the stations in 2046-2065; and an increase of $20 \%$, with an $8 \%$ standard deviation, in 2081-2100. Comparing LM projections and GCM projections showed that: (1) LM results had better spatial variability, being able to account for variations unnoticed by GCMs; (2) the standard deviations associated to LM projections for a single station were smaller than those associated to GCM projections.

\subsection{Source term analysis}

Table 9 and Fig. 8 show the results of the analysis of the reasons for the 2046-2065 increase in extreme OP intensities at the Bergen GFI station. Table 9 shows the source increase analysis for the individual model-runs; in Fig. 8 a boxplot gives an account for the ensemble performance. The analysis suggested that stability was the dominant factor behind the increase in OP extreme intensities, explaining about 20-60\% of the increase. The impact of temperature on the increase was remarkable, explaining about $20 \%$ of the increase. Temperature was the only variable whose increase was predicted by all model runs during extreme events, and the one with the smaller variability in its impact on the precipitation increase. In the face of climate change scenarios and global warming, this role of temperature in driving extreme OP increases was an important and robust result.

Wind speed and direction are important factors to consider in understanding a single model run, but there was large model-to-model uncertainty about the importance of both, as seen in Fig. 8. Negative values mean that the variable 


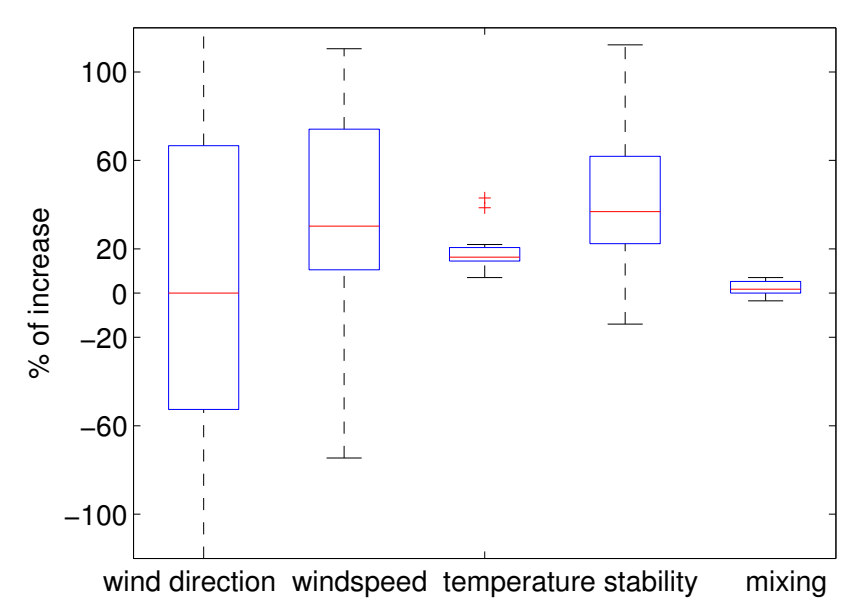

Fig. 8. Reasons for increase in extremes, 12-model-runs, Bergen, 2046-2065. Percent contributions for the increase (as part of the $100 \%$ increase for each model run) by the variables affecting precipitation. Edges of the box are 25th and 75th percentiles. Crosses indicate outliers.

reduced the increase, while values over $100 \%$ mean that, without a negative contribution from one or more other variables, the increase would have been bigger than our final result.

Wind direction had an important impact on extreme precipitation when taken into account for a single model run, but when considering the model-runs ensemble it gave an average impact of almost zero. Westerly winds tended to produce more precipitation over the whole study region because of the large-scale influence of topography. Local, small-scale topography can partially block moisture influx coming from some directions. For instance, at the Bergen station, LM shows an increase in OP when the wind direction is between $272^{\circ}$ and $269^{\circ}$, around $255^{\circ}$, around $231^{\circ}$, and between $217^{\circ}$ and $203^{\circ}$. These values were consistent with the observed values of wind direction during extreme events (like those in Sect. 3), although a much more accurate study would be needed for every station: (i) to compare the exact wind directions at which extreme events occur in LM and in observations; (ii) which wind directions reduce and which enhance precipitation.

Because of the significant variability in the wind speed values, including more simulations could yield a better picture of the wind's role; however, a possible outcome of adding more simulations could be that the positive and negative contributions from the models will cancel out in the same manner as they did for future wind directions, and emphasise the importance of stability and temperature even more.

\section{Discussion}

Several studies (Trenberth et al., 2003; Allan and Soden, 2008; Liu et al., 2009) have attributed the widespread increase in heavy precipitation to global warming.

Trenberth et al. (2003) noted that increases in surface temperature are stronger at higher latitudes. However, the atmospheric general circulation tends to move moisture from polar regions towards lower latitudes. Thus, there is a need for studies addressing whether the increasing moisture would be within the reach of extratropical storms that impact the high-latitude regions - a necessary condition for these regions' warming to have an impact on high-latitude precipitation.

Zhang et al. (2007) used observations and GCM simulations to determine whether there was an anthropogenic warming-induced change in precipitation over the 19251999 time period. The study, which examined precipitation over the whole planet, showed an increase in precipitation both in the observations and in the models for Norway, suggesting that these conditions might already have occurred during the last century's warming.

Our study addresses Trenberth's (2003) concerns in that it shows an increase of OP occurrences at high latitudes, and suggests that temperature change is responsible for about $20 \%$ of the future increase in extreme OP values. Temperature changes were found to be more robust than changes to the winds. Due to the uncertainties in wind change, it is difficult to establish how important they might be in future scenarios. Using wind values from an RCM or downscaling the IPCC wind values could address this problem.

The IPCC 2007 A1B scenario simulations predict that northern Europe above $55^{\circ} \mathrm{N}$ may experience high extremes of precipitation that are likely to increase in magnitude and frequency, especially during the winter (Christensen et al., 2007). This is consistent with our findings for western Norway, considering the roles of both temperature and stability, although the relative increase in frequency does not differ from winter to summer in our calculations.

It is important to point out that LM-based downscaling is a technique that can be applied to any possible GCM situation. The quality of its assessments depends directly on the quality of the GCM data that it is downscaling. LM improves the results in a significant way on the upwind side of the mountains at mid-high to high-latitudes, where thermal convection has not a significant influence on precipitation. However, LM must not be used for the assessment of lee-side stations, and might result not-suited for windside stations with low topography. The most significant drawback of this technique is the risk of using it incorrectly. Although the downscaling is quite simple and transparent, there should be considerable effort to determine whether the region of interest is suited to LM-downscaling. 


\section{Summary}

In this study, an efficient downscaling method, Smith and Barstad's Linear Model (2004), was used to physically downscale precipitation from 12 model runs of the IPCC 2007 A1B scenario over western Norway. The results showed an increase in Orographic Precipitation (OP) occurrence and an increase in the intensity of OP extremes over 74 grid points corresponding to Norwegian weather stations. The increase in intensity was found to be around $10 \%$ of the absolute values for the 2046-2065 scenario and around $15 \%$ for the 2081-2100 scenario, consistently with the general GCMs results. However, the improved resolution of LM allowed to perform an assessment of absolute future changes to extreme OP, based on the relative increase of the model results and on weather station observations.

The main reason for the increase of precipitation was more closely investigated for the Bergen meteorological station. The increase in moist air influx contributed significantly, whereas the contribution of wind direction was strongly model-dependent and tended to naught when modelaveraged. By separating out the factors that contributed to the source term, the results showed that stability and temperature increases were likely to be the main cause of increased influx, with temperature accounting for roughly $20 \%$ of the intensity increase in extreme OP for all models.

The present paper was meant as an introduction to possible uses of analysis connected to LM downscaling and showed methods that can be generally applied to many different model simulations.

Downscaling climate scenarios with LM seems to open up interesting possibilities for insight. In climatology, for instance, it can be used as a tool to evaluate GCM performance in the following areas:

i. The use of standard deviations of relative values instead of absolute ones makes it easier to compare models and point out those that may be underperforming;

ii. the transparent nature of LM makes it easy to see in which respect the models diverge and what impact that has on the downscaled results.

In weather forecasting, LM downscaling can be useful for present and future studies. Some examples include the following:

i. For the present by providing informations on how some variables can influence moist air influx, that might have been overlooked;

ii. for the future, because LM downscaling points out how the relationship of these variables to precipitation might change and indicates which variables have to be monitored in case need should arise to change the parameterisation and settings of the forecasting models.
Acknowledgements. This is publication no. A311 from the Bjerknes Centre for Climate Research.

The USGS 30 ARC-second Global Elevation Data, GTOPO30, are from the Research Data Archive (RDA), which is maintained by the Computational and Information Systems Laboratory (CISL) at the National Center for Atmospheric Research (NCAR). NCAR is sponsored by the National Science Foundation (NSF). The original data are available from the RDA (http://dss.ucar.edu) in dataset number ds758.0.

Many thanks to Jürgen Bader, Justin Wettstein and Anna Fitch for their valuable comments on the manuscript.

We also wish to thank Natascha Töpfer and the HESS Editorial Board, and the Editor, Jan Seibert, for their input, and the anonymous reviewers for their careful and attentive comments that helped to improve the scientific value of this paper.

Edited by: J. Seibert

\section{References}

Allan, R. P. and Soden, B. J.: Atmospheric Warming and the Amplification of Precipitation Extremes, Science, 321, 5895, doi:10.1126/science.1160787, 2008.

Andersen, P.: The distribution of monthly precipitation in Southern Norway in relation to prevailing H. Johansen weather types, Årbok Universitet Bergen, Mat. Naturv. Ser., 1972(1), 1-20, 1973.

Andersen, P.: Surface winds in southern Norway in relation to prevailing H. Johansen weather types, Meteorol. Ann., 6(14), 377399, 1975.

Barstad, I.: Southwesterly flows over southern Norway, Reports in meteorology and oceanography 7, Geofysisk Institutt, UiB, Doctoral Thesis, 2002.

Barstad, I. and Smith, R. B.: Evaluation of an Orographic Precipitation Model, J. Hydrometeorol., 6, 85-99, 2005.

Barstad, I., Grabowski, W. W., and Smolarkiewicz, P. K.: Characteristics of large-scale orographic precipitation, J. Hydrol., 340, 78-90, 2007.

Barstad, I., Sorteberg, A., Flatøy, F., and Déqué, M.: Precipitation, temperature and wind in Norway: dynamical downscaling of ERA40, Clim. Dynam., 33, 769-776, 2008.

Becker, M. and Bugmann, H.: Global Change and Mountain Regions - The Mountain Research Initiative, Global Terrestrial Observing System, Report n. 28, 1999.

Bousquet, O. and Smull, B. F.: Comparative study of two orographic precipitation events exhibiting significant upstream blocking during MAP, in Extended abstracts from the MAP meeting 2001, MAP Newsletter 15, 2001.

Christensen, J. H., Hewitson, B., Busuioc, A., Chen, A., Gao, X., Held, I., Jones, R., Kolli, R. K., Kwon, W.-T., Laprise, R., Magaña Rueda, V., Mearns., L., Menéndez, C. G., Räisänen, J., Rinke, A., Sarr, A., and Whetton, P.: Regional Climate Projections, in: Climate Change 2007: The Physical Science Basis, Contribution of Working Group I to the Fourth Assessment Report of the Intergovernmental Panel on Climate Change, edited by: Solomon, S., Qin, D., Manning, M., Chen, Z., Marquis, M., Averyt, K. B., Tignor, M., and Miller, H. L., Cambridge University Press, Cambridge, UK and New York, NY, USA, 2007. 
Coles, S.: An introduction to statistical modeling of extreme values, Springer, London, 2001.

Cooley, D. S.: Statistical Analysis of Extremes Motivated by Weather and Climate Studies: Applied and Theoretical Advances, Doctoral Thesis, University of Colorado at Boulder, Department of Applied Mathematics, 1-122, 2005.

Coppola, E. and Giorgi, F.: Climate change in tropical regions from high resolution time slice AGCM experiments, Q. J. Roy. Meteor. Soc., 131B, 3123-3146, 2005.

Crochet, P., Johannesson, T., Jonsson, T., Sigurdsson, O., Bjornsson, H., Palsson, F., and Barstad I.: Estimating the Spatial Distribution of Precipitation in Iceland Using a Linear Model of Orographic Precipitation, J. Hydrometeorol., 8, 1285-1306, 2007.

Cubasch, U., Meehl, G. A., Boer, G. J., et al.: Projections of Future Climate Change, in: Climate Change 2001: The Scientific Basis, Contribution of Working Group I to the Third Assessment Report of the Intergovernmental Panel on Climate Change, edited by: Houghton, J. T., Ding, Y., Griggs, D. J., et al., Cambridge University Press, 2001.

Déqué, M. and Piedelievre, J. P.: High-Resolution climate simulation over Europe, Clim. Dynam., 11, 321-339, 1995.

Georgis, J.-F., Roux, F., Chong, M., and Pradier, S.: Triple-Doppler radar analysis of the heavy rain event observed in the Lago Maggiore region during MAP IOP 2b, Q. J. Roy. Meteor. Soc., 129, 495-522, 2003.

Giorgi, F. and Mearns, L. O.: Introduction to special section: Regional climate modeling revisited, J. Geophys. Res., 104, 6335$6352,1999$.

Groisman, P., Knight, R. W., Easterling, D. R., Karl, T. K., Hegerl, G., and Razuvaev, V. N.: Trends in Intense Precipitation in the Climate Record, J. Climate, 18, 1326-1350, 2005.

Haylock, M. R., Cawley, G. C., Harpham, C., Wilby, R. L., and Goodess, C. M.: Downscaling Heavy Precipitation over the United Kingdom: A comparison of dynamical and statistical methods and their future scenarios, Int. J. Climatol., 26, 13971415, 2006

Jones, C.: Occurrence of Extreme Precipitation Events in California and Relationships with the Madden-Julian Oscillation, J. Climate, 13, 3576-3587, 2000.

Klein Tank, A. M. G. and Können, G. P.: Trends in Indices of Daily Temperature and Precipitation Extremes in Europe, 1946-1999, J. Climate, 16, 3665-3680, 2003.

Liu, S. C., Fu, C., Shiu, C.-J., Chen, J.-P., and Wu, F.: Temperature dependence of global precipitation extremes, Geophys. Res. Lett., 36, L17702, doi:10.1029/2009GL040218, 2009.

Maraun, D., Wetterhall, F., Ireson, A. M., Chandler, R. E., Kendon, E. J., Widmann, M., Brienen, S., Rust, H. W., Sauter, T., Themeß1, M., Venema, V. K. C., Chun, K. P., Goodess, C. M., Jones, R. G., Onof, C., Vrac, M., Thiele-Eich, I.: Precipitation downscaling under climate change. Recent developments to bridge the gap between dynamical models and the end user, Rev. Geophys., in press, doi:10.1029/2009RG000314, 2010.

Meehl, G. A., Stocker, T. F., Collins, W. D., Friedlingstein, P., Gaye, A. T., Gregory, J. M., Kitoh, A., Knutti, R., Murphy, J. M., Noda, A., Raper, S. C. B., Watterson, I. G., Weaver, A. J., and Zhao, Z.-C.: Global Climate Projections, in: Climate Change 2007: The Physical Science Basis, Contribution of Working Group I to the Fourth Assessment Report of the Intergovernmental Panel on Climate Change, edited by: Solomon, S., Qin, D., Manning, M.,
Chen, Z., Marquis, M., Averyt, K. B., Tignor, M., and Miller, H. L., Cambridge University Press, Cambridge, UK and New York, NY, USA, 2007.

Messerli, B. and Ives, J. D.: Mountains of the World: A Global Priority, Parthenon Pub. Group, New York, USA, 495 pp., 1997.

Murphy, J.: An evaluation of statistical and dynamical techniques for downscaling local climate, J. Climate, 12(8), 22562284.1999.

Roe, G.: Orographic Precipitation, Annu. Rev. Earth Pl. Sc., 33, 645-671, 2005.

Rotunno, R. and Ferretti, R.: Orographic effects on rainfall in MAP cases IOP 2b and IOP 8, Q. J. Roy. Meteor. Soc., 129, 373-390, 2003.

Salathé Jr., E. P.: Downscaling simulations of future global climate with application to hydrologic modelling, Int. J. Climatol., 25, 419-436, 2005.

Schmidli, J., Goodess, C. M., Frei, C., Haylock, M. R., Hundecha, Y., Ribalaygua, J., and Schmith, T.: Statistical and dynamical downscaling of precipitation: An evaluation and comparison of scenarios for the European Alps, J. Geophys. Res., 112, 1-20, 2007.

Smith, R. B.: The influence of mountains on the atmosphere, Adv. Geophys., 21, 87-230, 1979.

Smith, R. B.: A linear upslope-time-delay model for orographic precipitation, J. Hydrol., 282, 2-9, 2003.

Smith, R. B.: Progress on the theory of orographic precipitation, Geological Society of America, Special Paper, 398, 1-16, 2006.

Smith, R. B. and Barstad, I.: A linear theory of orographic precipitation, J. Atmos. Sci., 61, 1377-1391, 2004.

Solomon, S., Qin, D., Manning, M., Chen, Z., Marquis, M., Averyt, K. B., Tignor, M., and Miller, H. L.: Contribution of Working Group I to the Fourth Assessment Report of the Intergovernmental Panel on Climate Change, 2007, Cambridge University Press, Cambridge, UK and New York, NY, USA, 2007.

Trenberth, K. E., Dai, A., Rasmussen, R. M., and Parsons, D. B.: The changing character of precipitation, B. Am. Meteorol. Soc., 84, 1205-1217, 2003

Wang, Y., Leung, L. R., McGregor, J. L., Lee, D. K., Wang, W. C., Ding, Y., and Kimura, F.: Regional climate modeling: progress, challenges and prospects, J. Meteorol. Soc. Jpn., 82(6), 15991628, 2004.

Wilby, R. L. and Wigley, T. M. L.: Downscaling general circulation model output: A reappraisal of methods and limitations. In Climate Prediction and Agriculture, edited by: Sivakumar, M. V. K., Proceedings of the START/WMO International Workshop, 2729 September 1999, Geneva, International START Secretariat, Washington, DC, 39-68, 2000.

Wilby, R. L., Wigley, T. M. L., Conway, D., Jones, P. D., Hewitson, B. C., Main, J., and Wilks, D. S.: Statistical downscaling of general circulation model output: A comparison of methods, Water Resour. Res., 34, 2995-3008, 1998.

Zhang, X., Zwiers, F. W., Hegerl, G. C., Lambert, F. H., Gillett, N. P., Solomon, S., Stott, P. A., and Nozawa, T.: Detection of human influence on twentieth-century precipitation trends, Nature, 448 , 461-465, 2007. 